\title{
A Suspensão dos Processos e da Eficácia da Tese Fixada no Incidente de Resolução de Demandas Repetitivas - IRDR: Tentando Salvar O IRDR da Falácia da Vinculação
}

The Suspension of the Processes and the Effectiveness of the Thesis Established in the Incident of Resolution of Repetitive Demands - IRDR: Trying to Save the IRDR from the Fallacy of Binding

Paulo Afonso Brum Vaz

${ }^{1}$ Faculdade de Coimbra, Portugal

\section{Resumo}

\begin{abstract}
Neste artigo, a partir da matriz teórica sistêmica, pretendo discorrer criticamente acerca da problemática da suspensividade dos processos no Incidente de Resolução de Demandas Repetitivas - IRDR e seus percalços decorrentes da suspensão da eficácia da tese fixada no primeiro grau de jurisdição (tribunais de apelação), inerente aos recursos à superior instância. Almejo demonstrar que uma interpretação literal do $\S 1^{\circ}$ do art. 987 do CPC pode levar a situações verdadeiramente esquizofrênicas e a rupturas graves no microssistema de demandas repetitivas e precedentes, com incentivo manifesto às decisões conflitantes e anti-isonômicas, justamente o que se tentou evitar, tanto com a cultura de precedentes como com a suspensividade dos processos. Proponho que, depois de fixada a tese jurídica pelo tribunal de segundo grau, devam os Tribunais Superiores analisar criteriosamente, conforme as peculiaridades

da hipótese, a possibilidade de reconhecer a vinculação provisória desta tese, ao menos nos processos que estavam suspensos aguardando o desfecho do incidente, até que julguem o recurso e firmem a tese jurídica definitiva (estabilizada).

Palavras-chave:Incidente de resolução de demandas repetitivas; Suspensão dos processos; Obrigatoriedade da tese jurídica
\end{abstract}

\begin{abstract}
In this article, based on the systemic theoretical matrix, I intend to critically discuss the problem of suspension of processes in the Incident of Resolution of Repetitive Demands - IRDR and its problems resulting from the suspension of the effectiveness of the thesis established in the first degree of jurisdiction (courts of appeal), inherent to the appeals to the superior instance. I aim to demonstrate that a literal interpretation of $\$ 1$ of art. 987 of the CPC can lead to schizophrenic causes and severe disruptions without a microsystem of repetitive and precedent demands, with a clear incentive to conflicting and anti-isonomic decisions, precisely what was tried to avoid, both with the culture of precedents and with the suspension of processes. I propose that, after the legal thesis is fixed by the high court, the Superior Courts should carefully analyze, according to the peculiarities of the hypothesis, the possibility of recognizing the provisional connection of this thesis, at least in the cases that were suspended pending the judgment of the incident, until they judge the appeal and sign the final (stabilized) legal thesis.
\end{abstract}

Keywords: Repetitive demand resolution incident; Suspension of processes; Mandatory legal thesis;

\section{Introdução}

Para prevenir decisões conflitantes e tratamento diverso para conflitos judicializados idênticos (isonomia), no microssistema de demandas repetitivas, consoante o art. 982, I, do Código de Processo Civil - CPC, com a admissão do Incidente de Resolução de Demandas Repetitivas - IRDR, suspendemse os processos em tramitação pelo prazo de 1 (um ) ano (art. 980 e parágrafo único), salvo decisão 
fundamentada do relator em sentido contrário. ${ }^{1}$ Quanto ao recurso, o art. 987, $\$ 1^{\circ}$, do CPC, atribui efeito suspensivo ao acórdão do tribunal de segundo grau, com a simples interposição do recurso Especial ou Extraordinário, retirando-lhe a eficácia vinculativa até que transite em julgado o acórdão vinculante do tribunal superior, Superior Tribunal de Justiça - STJ, em caso de Recurso Especial, ou Supremo Tribunal Federal - STF, em caso de Recurso Extraordinário.

Dois problemas graves decorrem da interpretação destas regras de modo literal e não integrado dentro do microssistema de demandas repetitivas. Um, é a suspensão indiscriminada, que pode contribuir para atrasar o desfecho dos processos e causar danos irreparáveis às partes; outro, advém do vácuo que pode ocorrer entre o eventual levantamento da suspensão, pelo decurso de prazo, a admissão do recurso à superior instância, quando, então, os processos devem ser suspensos novamente.

Ocorre que, ressalvadas as raríssimas hipóteses de ausência de recursos contra o acórdão do tribunal (de origem) no IRDR, incumbe aos Tribunais Superiores dar a última palavra (estabilizar) na fixação das teses jurídicas que representarão precedentes vinculantes na solução de demandas repetitivas. Como no Brasil se tem uma judicialização intensa, para não dizer absurda, os Tribunais Superiores, insuficientes os filtros hoje existentes, não conseguem julgar a pletora de recursos que lhes chegam aos borbotões. ${ }^{2}$ A consequência inevitável é o atraso e a extrapolação do prazo legal. Segundo o relatório de atividades do STF de 2019, o tempo médio de tramitação anual dos processos foi de 323 dias. Consta que ainda $12 \%$ do total do acervo é composto por processos com mais de 5 (cinco) anos de ingresso no Tribunal. ${ }^{3}$

Neste artigo, a partir da matriz teórica sistêmica, discorro criticamente acerca da problemática da suspensividade dos processos no IRDR e seus percalços decorrentes da eficácia contida da tese fixada no primeiro grau de jurisdição (tribunais de apelação), inerente aos recursos à superior instância.

Intenta-se identificar situações em que há risco de rupturas graves no microssistema de demandas repetitivas e precedentes, com a possibilidade de surgirem decisões conflitantes e anti-isonômicas, justamente o que se almejou evitar com a cultura de precedentes e a regra geral de suspensividade dos processos.

Proponho que, depois de fixada a tese jurídica pelo tribunal de segundo grau solvendo o IRDR, ela vincule provisoriamente no âmbito da sua jurisdição, ao menos nos processos que estavam suspensos aguardando dito julgamento, segundo avaliação criteriosa dos Tribunais Superiores, que devem relevar para tal as peculiaridades do caso concreto. Em outras palavras, considerar que: a) a suspensão não é automática, nem obrigatória, e (b) a suspensão da eficácia do acórdão do tribunal de segundo grau que julga o IRDR pode ser mitigada ou modulada, sobretudo nos casos em que haja risco de decisões conflitantes.

O desiderato que nutre o presente ensaio é justamente tentar salvar o Incidente de Resolução de Demandas Repetitivas - IRDR da chamada "falácia da vinculação à tese jurídica" firmada pelo Tribunal de Segundo Grau, quando admitido recurso ao STJ, ou mesmo por este Tribunal, quando admitido Recurso Extraordinário no STF.

1 Esta suspensão se dá no âmbito da jurisdição do tribunal de instalação do IRDR. A suspensão nacional, a cargo do STJ e do STF, está disciplinada nos $\$ \S 3^{\circ}$ e $4^{\circ}$ do art. 982 do CPC.

2 Dados do Relatório de Gestão de 2019 mostram que o acervo do STJ, em 31.12.2019, era de 269.261 processos. Em 2019, foram julgados 18 recursos repetitivos e ficaram pendentes de julgamento 64. Disponível em: http://www.stj.jus.br $/$ sites/portalp/SiteAssets/Transparencia/Relatorios-de-gestao/Relatorio gestao 2019.pdf. Acesso em 04 ago. 2020.

No STF, o acervo, em 2019, era de 31.297 processos, destes 311 são temas com Repercussão Geral. Considerando que o Tribunal julgou o mérito de apenas 24 em 2019 e que ingressaram 41, pode-se estimar que a redução do estoque está ainda distante. Relatório de Atividades do STF de 2019. Disponível em: http://www.stf.jus.br/arquivo/cms/ centralDoCidadaoAcessoInformacaoGestaoEstrategica/anexo/2020 $01 \quad 24 \quad 13.08$ RelatoriodeAtividades2019 completo. pdf. Acesso em 04 ago. 2020.

3 Relatório de atividades do STF de 2019. Disponível em: http://www.stf.jus.br/portal/cms/verNoticiaDetalhe. asp?idConteudo=435934. Acesso em 04 ago. 2020. 


\section{Incidente de resolução de demandas repetitivas: noção e funções}

O Incidente de Resolução de Demandas Repetitivas - IRDR surgiu como inovação trazida pelo CPC de 2015, nessa que se pode chamar de quarta onda de reformas processuais, caracterizada pela criação de uma autêntica cultura de precedentes, cujos objetivos precípuos são a segurança jurídica e a isonomia no plano das decisões do Poder Judiciário, a serem alcançados pela superação da nominada jurisprudência lotérica e do solipsismo judicial, por meio de mecanismos que garantam estabilidade, coerência e integridade ao sistema jurisdicional, em uma perspectiva neoconstitucional de relevância máxima de direitos fundamentais e garantias dos litigantes.

A vinculação aos precedentes derivados de acórdãos de Resolução de Demandas Repetitivas (art. 927 do CPC) representa um avanço importante para os referidos ideais de estabilidade, coerência e integridade da jurisprudência dos Tribunais (art. 926 do CPC), tendo a grande virtude de contribuir para a redução do fenômeno da pulverização de demandas que versem sobre um mesmo assunto e ainda de contribuir para a redução da judicialização e o julgamento mais célere dos processos.

Enquanto técnica de julgamento molecular de demandas de múltipla repetição por um órgão colegiado, sobre questão de interpretação do direito, a fim de garantir a isonomia, a previsibilidade e a segurança jurídica, o IRDR pressupõe um iter relativamente complexo e imperativo (arts. 976 a 987 do CPC), como condição para que se chegue à definição da tese jurídica cujos fundamentos determinantes (ratio decidendi) serão de aplicação obrigatória nos processos pendentes e futuros (o precedente).

Os Tribunais de segundo grau, embora tenham papel importante na seleção dos casos e fixação das teses provisórias, que servirão de paradigmas para as definitivas a serem fixadas pelos Tribunais Superiores, funcionam mais como tribunais de passagem, porquanto, na maioria dos casos, havendo recurso excepcional, cumprirá a estes a tarefa mais relevante na estabilização da tese jurídica e criação do precedente vinculante. ${ }^{4}$

Não se pode afirmar, todavia, que os tribunais de segundo grau (TRFs e TJs) não desempenham, no microssistema de demandas repetitivas criado pelo CPC de 2015, a função criadora de precedentes vinculantes. Nos casos em que não há recurso à superior instância ou mesmo naqueles que tratem de questões de direito locais, a última palavra pode ser a destes tribunais. ${ }^{5}$

\section{O caráter não automático e obrigatório da suspensividadade: 0 imperativo da suspensão com bom senso}

Segundo preceitua o art. 982 do CPC, admitido o incidente, o relator suspenderá os processos pendentes, individuais ou coletivos, que tramitam no Estado ou na região, conforme o caso (inciso I).

A legitimidade da tese fixada no IRDR repousa justamente no procedimento, que, por ser complexo e amplamente dialético, tende a ser demorado. É possível estimar, pela experiência, que dificilmente um IRDR encontre o trânsito em julgado do acórdão (estabilização da tese jurídica fixada e seus motivos determinantes) antes de 4 (quatro) anos.

4 Ver, a propósito, LEMOS, Vinícius Silva. A falácia na aplicação da tese jurídica fixada em IRDR: a função meramente preparatória do incidente. Apud Processo, jurisdição e efetividade da justiça II [Recurso eletrônico on-line] organização CONPEDI/CESUPA. Coordenadores: Celso Hiroshi Iocohama; Sérgio Henriques Zandona Freitas - Florianópolis: CONPEDI, 2019.

5 Marinoni sustenta que os precedentes vinculantes somente podem ser criados pelos Tribunais superiores (MARINONI, Luiz Guilherme. O "problema” do incidente de resolução de demandas repetitivas e dos recursos extraordinário e especial repetitivos. Revista de Processo. vol. 249, ano 40. p. 399-419. São Paulo: RT, nov. 2015). No sentido contrário, justamente esgrimindo com os mesmos argumentos que vim de referir, LEMOS, Vinícius Silva. A falácia na aplicação da tese jurídica fixada em IRDR: a função meramente preparatória do incidente. Apud Processo, jurisdição e efetividade da justiça II [Recurso eletrônico on-line] organização CONPEDI/CESUPA. Coordenadores: Celso Hiroshi Iocohama; Sérgio Henriques Zandoná Freitas - Florianópolis: CONPEDI, 2019. 
O IRDR foi adrede criado para dar segurança jurídica, mas a demora no seu desfecho - a suspensão pode perdurar até o trânsito em julgado de eventual acórdão em RE no STF - dissemina, em frequentes situações, ainda maior insegurança e instabilidade. Este risco sistêmico demanda uma séria reflexão acerca da suspensão irrestrita (para não dizer, irrefletida) dos processos, que pode gerar demora na solução final e consequentes possibilidades de perecimento de direitos, em que pese seja viável o pedido de tutelas provisórias durante a suspensão. É que a demora sempre produz danos marginais decorrentes do prolongamento do estado litigioso.

A primeira questão que pode gerar alguma polêmica é a obrigatoriedade ou não da suspensão. Embora não seja automática, pois depende de decisão do relator do incidente, entendo que a regra deve ser a suspensão. A suspensividade é fundamental, ninguém duvida disso, para que o culto aos precedentes tenha maior eficácia e alcance seus objetivos de segurança jurídica e isonomia. Não teria muito sentido se, enquanto não se decide o IRDR, os processos sobre o mesmo tema "afetado" pudessem ser julgados. Estar-se-ia postergando para o futuro a eficácia do incidente. A eficácia seria apenas prospectiva. A possibilidade de uma futura ação rescisória para aplicação do precedente é ainda assunto que precisa evoluir. Portanto, a suspensividade é, podemos assim dizer, corolário intrínseco do sistema de precedentes, embora represente um risco de violação ao prazo razoável do processo enquanto direito constitucional fundamental. A bem da verdade, há consenso sobre ser a suspensão dos processos iguais a regra geral na admissão do IRDR. Não discrepa a doutrina. O que se discute é se situações excepcionais autorizariam excepcionar-se tal regra.

Em que pese estar a suspensão prevista como regra no microssistema de demandas repetitivas, ela não é imperativa e requer ponderada reflexão acerca da sua necessidade. ${ }^{6}$ Tanto é assim que alguns tribunais têm relativizado a regra da suspensão da tramitação de todos os processos relacionados ao tema que será julgado como paradigma. Casos há em que a suspensão pode acarretar graves prejuízos para os processos individuais ou coletivos já em trâmite, violando princípios constitucionais processuais como celeridade, economia processual e, sobretudo, postergando o exercício de direitos fundamentais judicializados, como é o caso dos Direitos da Seguridade Social, que são objeto de mais da metade dos processos que tramitam na Justiça Federal. Bem lembram Dierle Nunes e Souza Viana:

\begin{abstract}
Não se pode encarar toda a litigiosidade repetitiva como se a mesma se reduzisse à sua hipótese soft que trata de questões patrimoniais nas quais bastaria determinar, por exemplo, se há possibilidade de penhora de vaga de garagem autônoma, mas também de litigiosidade repetitiva hard que envolve auferimento de direitos fundamentais como os que tratam da judicialização da saúde. Ademais, "o sentido literal da lei não pode constituir limite à interpretação conforme", quando sua análise inviabiliza a aplicação de normas constitucionais. Não se pode enxergar como fundamento principal da norma do artigo 1.037, II, CPC/2015 o gerenciamento de processos repetitivos, visando tão só eficiência quantitativa, mas a preservação de coerência e integridade (artigo 926) que não macule o auferimento de direitos fundamentais como na hipótese aqui em comento (suspensão de ações em que se busca medicamentos). ${ }^{7}$
\end{abstract}

O STF, na Questão de Ordem no Recurso Extraordinário com Agravo 966.177 - da relatoria do Min. Luiz Fux, entendeu, por maioria, que a suspensão nos processos afetados em Repercussão Geral não é automática e nem obrigatória. "A suspensão não consiste em consequência automática e necessária do reconhecimento da repercussão geral realizada com fulcro no caput do mesmo dispositivo, sendo da discricionariedade do relator do recurso extraordinário paradigma determiná-la”.

6 Discordo de Ravi Peixoto quando afirma que a suspensão tem caráter obrigatório ao referir: "É necessário ressaltar que não há opção entre suspender ou não os processos após a instauração do IRDR. O papel do relator é apenas o de, admitido o IRDR, declarar a suspensão dos processos. Não se trata de alguma espécie de tutela de urgência, mas de uma consequência automática da instauração do incidente" (PEIXOTO, Ravi. O IRDR e a suspensão de processos. Disponível em: emporiododireito.com.br /o-irdr-e-a-suspensao-de-processos-por-ravi-peixoto/. Acesso em: 04 ago. 2020).

7 Dierle Nunes e Antônio Aurélio de Souza Viana. Suspensão integral de processos em recursos repetitivos preocupa. Consultor Jurídico - CONJUR - 31 de maio de 2017, disponível em: https://www.conjur.com.br/2017-mai-31/opiniaosuspensao-integral-processos-repetitivos-preocupa. Acesso em: 03 ago. 2020. 
O argumento esgrimido pelo Min. Fux foi no sentido de que as suspensões podem ficar por tempo indeterminado com a revogação do $\$ 10$ do art. 1035 da redação original do CPC, que estabelecia o prazo de um ano para julgamento, pela Lei no 13.256, de 2016.

Em relação à repercussão geral no STF, na regra original do novo CPC previa que, não ocorrendo o julgamento em um ano, a contar do reconhecimento da repercussão geral, cessaria a suspensão dos processos em todo o território nacional. Esta regra, contida no $\$ 10$ do art. 1.035, foi revogada pela Lei $\mathrm{n}^{\mathrm{o}}$ 13.256, de 2016, antes mesmo de entrar em vigor o Código. Com isso, a regra do $§ 9^{\circ}$, estabelecendo o prazo de 1 (um) ano para julgamento do recurso afetado em repercussão geral, remanesceu sem qualquer consequência prática, na medida em que o atraso não implica que os processos suspensos voltem a ter curso normal.

Justamente essa possibilidade de ficar indefinida no tempo a suspensividade na Repercussão Geral é que não ocorre no IRDR, porque o legislador estabeleceu o prazo de suspensão e a consequência do decurso de prazo: voltam os processos a tramitar. Isso não representa dizer que o IRDR não corre o risco de conduzir a solução do conflito a uma suspensão por tempo indeterminado, como será visto adiante.

O artigo 980 do CPC estabelece o prazo de 1 (um) ano para o julgamento do IRDR, com preferência sobre os demais feitos, ressalvados os que envolvam réu preso e os habeas corpus. E, no parágrafo único do referido artigo, encontra-se a regra decisiva: "Superado o prazo previsto no caput, cessa a suspensão prevista no art. 982, salvo decisão fundamentada do relator em sentido contrário”.

Portanto, passado 1 (um) ano da admissão do IRDR, se o relator não decidir pela manutenção fundamentada da suspensividade, estará, ipso facto, levantada a suspensão dos processos.

Segundo o $\S 5^{\mathrm{o}}$ do art. 982: “Cessa a suspensão a que se refere o inciso I do caput deste artigo se não for interposto recurso especial ou recurso extraordinário contra a decisão proferida no incidente". Esta é, portanto, ao lado do decurso de prazo de um ano, a segunda hipótese de levantamento da suspensão. Aplica-se a hipótese que ocorrer primeiro. Se a suspensão, antes, já estiver levantada pelo decurso de prazo, obviamente não incide a segunda hipótese.

A terceira hipótese de suspensão decorre do $\$ 3^{\circ}$ do art. 982, que possibilita aos legitimados para a instauração requererem a suspensão nacional dos processos em tramitação sobre a questão objeto do incidente já instaurado.

A quarta hipótese de suspensão ocorre por força do $§ 1^{1}$ do art. 1.036, que dispõe sejam os demais processos tramitação na jurisdição do tribunal suspensos, depois de selecionados, pelo Presidente ou Vice-Presidente, os recursos representativos da controvérsia que serão remetidos aos tribunais superiores. Esta hipótese ocorre, mutatis mutandis, quando admitido o recurso extremo, que ostenta a condição intrínseca, ex lege, de repercussão geral quanto à matéria constitucional.

Tem-se notado o uso indevido da técnica suspensiva, melhor dizendo, o abuso de tal técnica e o desuso das possíveis modulações que permitiriam o arrefecimento dos efeitos nocivos do tempo, intrínsecos ao rito do IRDR, como já se disse.

A suspensão dos processos, como a vejo, constitui um mecanismo de harmonização das eventuais colidências entre os princípios da segurança jurídica e da isonomia e os princípios da efetividade e do prazo razoável no processo, que se traduzem em correlatos direitos fundamentais do litigante com invergadura constitucional. Como tal, não se trata de uma regra absoluta, que, a pretexto de garantir segurança e isonomia, possa aniquilar a efetividade e o direito constitucional fundamental ao prazo razoável para a solução do processo, princípios também estruturantes do novo processo civil.

A suspensão não é de todo o processo, mas apenas da parte que diga respeito à matéria de direito afetada no IRDR. É bom lembrar que o novo processo civil expressamente rompeu com o princípio da unidade do julgamento de mérito (art. 356), além de ter-se filiado à teoria dos capítulos da sentença, o que permite o julgamento parcial de mérito e o cumprimento imediato da parte autônoma transitada em julgado. ${ }^{8}$ Assim, sempre que for possível identificar um pedido autônomo que não fique prejudicado

8 Ver, a propósito, decisão vinculante do STF no RE 1.205.530/SP, considerando constitucional a expedição de precatórios para que a Fazenda pública pague a parcela incontroversa e autônoma de uma dívida decorrente de decisão judicial. Também, com espectro mais amplo, a tese jurídica fixada no IRDR tema 18 no TRF4 - $\underline{50486972220174040000 /}$ 
pelo eventual julgamento de outro pedido, como ocorre nos casos de cumulação simples (ou mesmo alternativa) do pedido, impõe-se explicitar essa circunstância na decisão que determina a suspensão dos processos ou, se ausente tal advertência, compete ao juiz da causa suspender apenas o que precisa ser suspenso. ${ }^{9}$

Neste sentido o Enunciado no 205 do FPPC: Havendo cumulação de pedidos simples, a aplicação do art. 982, I e § 3º, poderá provocar apenas a suspensão parcial do processo, não impedindo o prosseguimento em relação ao pedido não abrangido pela tese a ser firmada no incidente de resolução de demandas repetitivas. (Grupo: Incidente de Resolução de Demandas Repetitivas e Assunção de Competência).

Não é incomum a inadequada suspensão até de processos em fase de cumprimento da sentença, quando a matéria altercada no IRDR diz respeito ao processo de conhecimento e o processo já foi julgado, não havendo a mínima possibilidade de ser afetado pelo resultado do julgamento do incidente. Claro que uma futura e eventual Ação Rescisória poderá rescindir a sentença ou acórdão, mas essa possibilidade não afeta o cumprimento da sentença antes do tempo. ${ }^{10}$

Medidas simples como possibilitar que o processo tenha curso normal até o momento da sentença, como adotou o Tribunal Regional Federal da 4⿳a Região após a admissão do IRDR n⿳o 15 (AG n⿳o 5019431-53.2018.4.04.0000, Turma Regional Suplementar de Santa Catarina, Relator Des. Federal Celso Kipper, juntado aos autos em 21/03/2019), ou mesmo a suspensão apenas dos processos com recurso no tribunal, a exemplo do que determinou a Terceira Seção do TRF4 por ocasião da admissão do IRDR no 24 (IRDR nº 5046607-70.2019.4.04.0000, Terceira Seção, Relator Desembargador Federal Fernando Quadros da Silva, juntado aos autos em 29/05/2020), hipótese em que se pode aplicar o precedente vinculante sem risco de tratamento não igualitário, são salutares e contribuem para que o incidente seja menos traumático. Em casos extremos, a própria suspensão dos processos, é dizer, a prevenção do risco de decisões conflitantes e anti-isonômicas pode revelar-se mais prejudicial do que permitir que os processos tenham curso normal, já que haverá posteriormente a possibilidade de aplicação do precedente vinculante.

Trago à colação um julgado recente do TRF4, em que se discutiu a modulação da suspensão:

AGRAVO DE INSTRUMENTO. PREVIDENCIÁRIO. PROCESSUAL CIVIL. PROSSEGUIMENTO DA AÇÃO. POSSIBILIDADE. MATÉRIA SUBMETIDA AO RITO DOS RECURSOS REPETITIVOS NO STJ. MODULAÇÃO DA SUSPENSIVIDADE. 1. Embora pendente de julgamento no STJ o Tema 1.005 ("Fixação do termo inicial da prescrição quinquenal, para recebimento de parcelas de benefício previdenciário reconhecidas judicialmente, em ação individual ajuizada para adequação da renda mensal aos tetos fixados pelas Emendas Constitucionais 20/98 e 41/2003, cujo pedido coincide com aquele anteriormente formulado em ação civil pública”), considerando tratarse de questão acessória e a fim de garantir a razoável duração do processo, a celeridade, a efetividade e, sobretudo, a prioridade de tramitação dos feitos, é cabível determinar-se o regular prosseguimento do feito, cabendo ao juízo

TRF: É legalmente admitido o imediato cumprimento definitivo de parcela transitada em julgado, tanto na hipótese de julgamento antecipado parcial do mérito ( $\$ 2^{\circ}$ e $3^{\circ}$ do art. 356 do CPC), como de recurso parcial da Fazenda Pública, e o prosseguimento, com expedição de RPV ou precatório, na hipótese de impugnação parcial no cumprimento de sentença que reconheça a exigibilidade de quantia certa (art. 523 e $\$ \S 3^{\circ}$ e $4^{\circ}$ do art. 535 do CPC), respeitada a remessa oficial, nas hipóteses em que necessária, nas ações em que é condenada a Fazenda Pública na Justiça Federal, nos Juizados Especiais Federais e na competência federal delegada (Relator p/ o acórdão Desembargador Federal Paulo A. B. Vaz).

9 Ver, a propósito, ALVIM, Teresa Arruda. CPC abre debate sobre alcance de suspensão de ações em repetitivos. Consultor Jurídico - Conjur. Disponível em: https://www.conjur.com.br/2017-jun-11/teresa-alvim-cpc-abre-debatesuspensao-acoes-repetitivos. Acesso em: 04 ago. 2020.

10 Bem lembra Christian Barros Pinto, que, "uma vez encerrada a fase cognitiva, naquela mesma relação nenhum julgamento será mais cabível (ou necessário), sendo certo que o que naqueles processos agora se busca é a satisfação de uma obrigação já revelada em pronunciamento judicial sobre o qual não pende mais discussão, porque já transitado em julgado. Portanto, não há mais tese jurídica a ser aplicada àqueles casos concretos. A atividade do Judiciário, depois do retorno dos autos à origem deve restringir-se aos atos necessários à entrega, aos credores, do quantum a eles devido, na exata extensão da decisão judicial transitada em julgado que substancia o título executivo" (PINTO, Christian Barros. Impossibilidade de sobrestamento de cumprimento de sentença pela admissão de Incidente de Resolução de Demandas Repetitivas. Disponível em: https://www.academia.edu/32058320/Impossibilidade de sobrestamento de cumprimento de senten\%C3\% A7a pela admiss\%C3\%A3o de Incidente de Resolu\%C3\%A7\%C3\%A3o de Demandas Repetitivas. Acesso em: 15 set. 2020). 
de origem, na fase de cumprimento, e à vista e nos limites do que vier a ser decidido pela Corte Superior, autorizar o pagamento dos valores atrasados. 2. Técnica de modulação da suspensividade inerente ao julgamento dos recursos repetitivos, que visa a evitar prejuízo às partes, sem ensejar o risco de decisões conflitantes e tratamento anti-isonômico a situações idênticas, conforme julgados deste Tribunal (TRF4, Agravo de Instrumento n⿳ํㅡㄴ 014569 68.2020.4.04.0000, TURMA REGIONAL SUPLEMENTAR DE SANTA CATARINA, Desembargador Federal PAULO AFONSO BRUM VAZ, unânime, juntado aos autos em 21.07.2020).

Resumindo, entre paralisar os processos por anos a fio ou contar com eventuais decisões que não estejam perfiladas com a tese jurídica que vier a ser fixada, pode ser mais interessante optar pela segunda opção, como fez o Tribunal de Justiça de São Paulo - TJSP, no IRDR no 0023203-35.2016.8.26.0000, Tema $\mathrm{n}^{\mathrm{o}} 4$, com densa fundamentação de seu relator que aqui colaciono na integra:

Finalmente, entendo desnecessária e imprópria a determinação de suspensão dos processos pendentes, individuais ou coletivos, que tramitam em todo o Estado de São Paulo (art. 982 I, NCPC). Após refletir detidamente sobre a questão, justifico as razões que me levaram a propor a não suspensão dos milhares de processos pendentes. São dezenas de milhares de processos em andamento perante a Justiça Comum e os Juizados Especiais no Estado de São Paulo, versando sobre os efeitos do atraso da entrega de unidades autônomas, produto do período de extraordinária expansão imobiliária entre os anos de 2.010 a 2.014. Parte dos temas objeto do incidente tem jurisprudência consolidada e sumulada por este próprio Tribunal de Justiça, ou enunciados dos Colégios Recursais dos Juizados Especiais. Explicitei acima as razões pelas quais propus a admissão, para fins de IRDR, de temas já sumulados por este Tribunal de Justiça. O incidente surtirá efeitos processuais distintos e mais vigorosos do que as súmulas de jurisprudência. A realidade é que os julgamentos de Primeira Instância que violam as Súmulas jurisprudenciais aprovadas por este Tribunal de Justiça, embora existam, são francamente minoritários. A paralisação de todos os processos do Estado de São Paulo por até um ano provocaria efeito inverso à celeridade e segurança que o instituto do IRDR almeja. Para fins de evitar a instabilidade e insegurança jurídica de franca minoria de julgamentos dissonantes, seria suspensa a maioria dos julgamentos que se filiam ao entendimento já sumulado. Em última análise, com o escopo de evitar o risco a isonomia e a segurança jurídica de número não expressivo de feitos, se paralisaria pelo prazo de até um ano (sujeito ainda a Recursos Especial e Extraordinário dotados de efeito suspensivo) a imensa maioria dos feitos que já seguem a jurisprudência consolidada e sumulada do Tribunal de Justiça. Persiste em doutrina fundada dúvida acerca da paralisação dos feitos, se consequência necessária ou facultativa, a critério da Turma Julgadora que decidirá o juízo de admissibilidade do incidente. Pontua Rodolfo de Camargo Mancuso que se discute, "em doutrina, se tal sobrestamento é de ser deixado ao prudente discernimento do relator, conforme as peculiaridades da espécie, ou se é providencia a ser necessariamente por ele implementada” (Incidente de Resolução de Demandas Repetitivas, Editora RT, p 242). Após relacionar os posicionamentos de diversos autores, conclui, com acerto, que a virtude se encontra no meio-termo, ou seja, implica em que se dê o devido peso à prevalência do interesse público e social que permeia o IRDR. De um lado, deve ser sopesada a possibilidade de se colocar em risco a isonomia e a segurança jurídica. De outro lado, deve o relator ponderar o risco concreto que o andamento das ações em paralelo pode provocar à boa ordem judiciária (obra citada, p. $242 / 243)$. No caso concreto, repito que o risco de quebra do princípio da segurança jurídica em virtude de pequeno número de casos dissidentes da jurisprudência hoje dominante não sobrepuja o sacrifício que milhares de credores sofreriam, além da violação à boa ordem judiciária, caso seus processos permanecessem paralisados pelo prazo de um ano. Filio-me por isso aos ensinamentos de Nelson Nery Júnior e Rosa Maria de Andrade Nery, para quem “o relator do IRDR, assim que admitido o incidente pelo órgão colegiado, poderá determinar a suspensão de todos os processos, individuais e coletivos, que tramitam na região (TRF) ou no Estado (TJ) que contenham a mesma questão jurídica posta para análise." (Comentários ao CPC, Editora RT, p. 1.972; cfr. também José Miguel Garcia Medina, Novo Código de Processo Civil Comentado, 2.015, nota ao artigo 982, p. 1.327). Proponho, portanto, que o IRDR se processe, em caráter excepcional, sem a suspensão das ações que tenham por objeto os mesmos temas que correm no Estado de São Paulo. É o voto que submeto à D. Turma Especial da 1ª . Seção de Direito Privado do Tribunal de Justiça de São Paulo. FRANCISCO LOUREIRO Relator.

O STJ, no Recurso Especial nº 1.729.593-SP, oriundo do já referido IRDR encaminhado pelo TJ/ $\mathrm{SP}$, envolvendo demandas que tratam de aspectos ligados à compra e venda de imóveis na planta e às controvérsias acerca dos efeitos na entrega do bem, apesar de reconhecer que a suspensão de todos os processos que versem sobre o mesmo tema possa ser um dos efeitos da decisão de afetação do recurso como repetitivo, entendeu como inconveniente a adoção dessa medida no caso em questão e, de maneira 
ponderada, explicitou as argumentações que embasaram tal decisão no sentido de que: a) a paralisação de todos os processos no país que versem sobre o tema poderia acarretar efeito diferente da celeridade e da segurança jurídica que o julgamento sob o rito dos recursos repetitivos anseia; b) a suspensão impediria que as partes envolvidas nas demandas que tratam de questões de moradia pudessem tentar obter acordo, o que seria uma "iniciativa salutar, que visa colocar fim aos litígios"; e c) deveria ser considerado o risco potencial do encerramento das atividades de parte das empresas demandadas, devido ao desaquecimento do setor imobiliário, que só se agravaria com a suspensão em massa de um elevado número de demandas tratando desse tema. ${ }^{11}$

Ao que tudo indica, existe no STJ uma tendência de análise casuística da questão da suspensividade, cujo pano de fundo é assegurar a isonomia de tratamento aos jurisdicionados em situações idênticas. Esta tendência procura levar em consideração as variáveis específicas presentes na matéria afetada, como são o risco de decisões conflitantes e a possibilidade de reversão destas decisões, ponderando também o eventual sacrifício de direitos materiais e processuais, além das garantias fundamentais constitucionais dos litigantes e a própria eficiência do Poder Judiciário.

Dierle Nunes e Antônio Aurélio Viana propõem excepcionar-se a regra da suspensividade, modulando-se os seus efeitos quando se discute acerca de direitos impostergáveis, como é o caso dos direitos fundamentais sanitários, para que não corram risco de perecimento as garantias fundamentais processuais do acesso à justiça, da efetividade e do tempo razoável. ${ }^{12}$

Vale aqui lembrar que a decisão de suspensão do processo é recorrível. O STJ, em acórdão esclarecedor, pontificou que tal decisão pode ser inquinada por agravo de instrumento, mas somente após o cumprimento das etapas previstas nos parágrafos 9o a 13 do artigo 1.037 do Código de Processo Civil (CPC). Para a Terceira Turma do Superior Tribunal de Justiça (STJ), no REsp. no 1.846.109 - SP, Relatora Ministra Nancy Andrighi, julgado em 10/12/2019, as regras para a parte pedir o prosseguimento do seu processo, quando a suspensão decorre da afetação de recurso repetitivo, também são aplicáveis no caso de IRDR. "Na hipótese em exame, não existe diferença ontológica e nem tampouco justificativa teórica para a assimetria entre a alegação de distinção formulada em virtude de afetação para julgamento sob o rito dos recursos repetitivos e em razão de instauração do incidente de resolução de demandas repetitivas", reconheceu a Min. Nancy Andrighi.

Segundo o voto da eminente Ministra, o legislador estabeleceu um detalhado procedimento para a parte requerer a distinção, que pode ser sintetizado em cinco etapas: intimação da decisão de suspensão; requerimento da parte pedindo a distinção; abertura de contraditório; prolação de decisão sobre o requerimento, e, se for o caso, interposição do agravo. Estas etapas precisam ser seguidas para que seja admitido o agravo de instrumento.

Concluindo, sem colocar em risco a regra geral da suspensividade, propõe-se: 1) atenção para o que precisa ser suspenso, a fim de que não se suspenda mais do que o necessário para o cumprimento do desiderato do sobrestamento; 2) ampla aplicação de medidas modulatórias de suspensividade, ao lado das hipóteses legais que visam a proteger situações de urgência (tutelas provisórias), e 3) a nãosuspensividade nos casos em que: a) haja risco fundado de perecimento de direito, sobretudo os direitos fundamentais sociais, individuais e coletivos; b) o custo-benefício da suspensão seja negativo, diante do diminuto risco de decisões conflitantes.

\section{Problema da suspensão ope legis da eficácia do acórdão do tribunal de origem diante da admissão do recurso à superior instância}

É preciso distinguir, se é que alguém confunde, entre a suspensão dos processos, prevista no art. 980 do CPC, e o efeito suspensivo ope legis dos recursos especial e extraordinário ao STJ e ao STF, respectivamente, tal como previsto no art. 987, § 1º, do CPC, que diz respeito à eficácia da decisão

11 Tratava-se do Tema 4, IRDR nº 0023203-35.2016.8.26.0000 do TJ/SP, que já foi julgado no STJ.

12 Dierle Nunes e Antônio Aurélio de Souza Viana. Suspensão integral de processos em recursos repetitivos preocupa. Consultor Jurídico, 31 de maio de 2017, disponível em: https://www.conjur.com.br/2017-mai-31/opiniao-suspensao-integralprocessos-repetitivos-preocupa. Acesso em: 03 ago. 2020). 
(acórdão) do IRDR. Portanto, é possível o prosseguimento dos processos concomitamente à interposição dos recursos extremos.

Esta singela distinção, sem qualquer complexidade, não tem sido feita de forma adequada. Vê-se com frequência afirmativas categóricas no sentido de que o CPC determina a suspensão dos processos com a interposição recurso excepcional à superior instância, quando, na verdade, o referido dispositivo legal trata do efeito suspensivo da eficácia da decisão do IRDR.

O Regimento Interno do STJ dispõe que: "A suspensão vigorará até o trânsito em julgado da decisão proferida no incidente de resolução de demanda repetitiva” (art. 271-A, § $3^{\circ}$ ), colocando por terra a previsão legal de suspensão máxima pelo prazo de 1(um) ano, conforme o art. 980 do CPC. A toda evidência, referida disposição regimental contraria o texto legal.

Por não haver a suspensão automática dos processos, a interposição de recurso à superior instância contra o acórdão que fixa a tese jurídica no IRDR no tribunal de origem, implicando, ope legis, a suspensão de sua eficácia, gera um problema sério: sem suspensão, os processos podem ser julgados de qualquer maneira, inclusive, e o que é mais grave, contrariando a tese jurídica fixada, que se encontra com a eficácia suspensa.

É preciso lembrar que o efeito suspensivo é, em princípio, automático e independe da admissão do recurso Especial ou Extraordinário. Trata-se da figura do efeito suspensivo ope legis, em que a suspensão decorre da simples previsão legal do recurso com efeito suspensivo, e não da decisão que o admite (ope judicis). O efeito suspensivo ope legis recebe essa nomenclatura por derivar da lei, ou seja, decorre da hipótese normativa de cabimento do recurso.

A mera possibilidade de uso do recurso, em função de sua previsão legal, já retira a eficácia da decisão que será recorrida. Assim, decisões impugnáveis por recursos dotados, por lei, de efeito suspensivo já nascem com seus efeitos 'paralisados'. Estas decisões somente passam a produzir efeitos em quatro hipóteses: a) se o recurso não for interposto; b) se ele não for inadmitido; c) se houver decisão do tribunal competente para analisar o recurso, suprimindo-lhe o efeito suspensivo, e d) se ele vier a ser improvido.

O ponto controvertido diz respeito, então, à vinculação à tese provisoriamente firmada no IRDR na "janela" que eventualmente pode se criar com o levantamento da suspensão por decurso de prazo até que a Presidência ou Vice-Presidência do Tribunal determine nova suspensão na forma do $\S 1^{\circ}$ do art. 1.036 do CPC, ao admitir a subida de recursos sobre a matéria controvertida para fins de afetação e julgamento pela sistemática dos recursos repetitivos.

Embora seja certo que os tribunais de segundo grau exercem uma função mais preparatória e de filtragem dos casos vocacionados à pacificação pela via do precedente a ser firmado pelos tribunais superiores pelo regime dos recursos repetitivos, não se lhes pode aviltar as atribuições de maneira a tornar sua tese jurídica um tipo de decisão que "somente existe para provocar o recurso". Julgado o recurso, ela desaparece por completo.

Veja-se que o art. 985 do CPC dispõe que, julgado o incidente, a tese jurídica será aplicada a todos os processos individuais ou coletivos que versem sobre idêntica questão de direito e que tramitem na área de jurisdição do respectivo tribunal (I). Com efeito, sustentar a ausência de vinculação, ainda que provisória, representa vilipendiar o texto, ignorá-lo iniciando uma interpretação do marco zero, técnica que não encontra respaldo em nenhum modelo hermenêutico que se conheça.

A vocação natural do IRDR é a de formar tese jurídica obrigatória de aplicação local ou regional, somente assumindo conotação nacional se houver deliberação do tribunal superior. Se não existisse vinculação, ao menos provisória, à tese jurídica firmada pelo tribunal de segundo grau, o microssistema parcial de demandas repetitivas e precedentes ficaria completamente esquizofrênico e paradoxal.

Vejamos o máximo contrassenso: os processos permanecem suspensos por um ano para impedir decisões conflitantes e garantir a segurança jurídica e a isonomia. Passado esse ano e já julgado o IRDR, ocorrendo o levantamento da suspensão, até que suceda nova suspensão, com a admissão do recurso à superior instância, voltam a ser permitidas as tais decisões conflitantes e a insegurança jurídica. 
Logo agora que já se tem uma tese jurídica firmada depois de amplo debate no IRDR! De que valeu a suspensão?

Fixada a tese jurídica pelo tribunal de segundo grau, supondo que os processos não estão mais sobrestados, ${ }^{13}$ ao juiz que vai julgar o processo (antes suspenso), se lhe apresentam três possibilidades: a) julgar conforme o entendimento sufragado pelo seu Tribunal em sede de IRDR, depois de ampla discussão e atendido o procedimento legal legitimador; b) julgar contrariando o entendimento do seu tribunal, sob o argumento de que está com a eficácia suspensa; c) determinar o sobrestamento do processo para aguardar o trânsito em julgado da decisão dos tribunais superiores no recurso excepcional.

A mim, parece que a primeira hipótese é a mais consentânea com os postulados sistêmicos da cultura de precedentes no microssistema de demandas repetitivas. Afinal, o acórdão do tribunal de segundo grau é mais do que um mero aresto persuasivo, pois se encontra a meio caminho para se consagrar como um precedente vinculante.

É possível que ocorra uma "janela” sem suspensão dos processos mesmo depois de firmada a tese jurídica, em sede de recurso repetitivo no âmbito do STJ, em caso de admissão de Recurso Extraordinário dirigido ao STF, sobrevindo a dúvida quanto à vinculação. Isso ocorreu, na prática, no tema 1007, cujo repetitivo foi julgado pelo STJ firmando a tese jurídica, mas, ato contínuo, a própria relatora admitiu o RE ao STF, suspendendo apenas os processos em grau de recurso. Como devem ser julgados os processos no primeiro grau de jurisdição, já que não estarão suspensos?

Parece inequívoco que não se pode ignorar a tese firmada pelo STJ em sede de recurso repetitivo, ao menos até que o STF estabilize definitivamente a tese jurídica firmado, confirmando-a ou não. Foi neste sentido a decisão do TRF4 justamente em um caso em que o STJ, depois de firmar a tese em recurso repetitivo, admitiu o Recurso Extraordinário ao STF e manteve o sobrestamento dos processos apenas na fase recursal, como isso autorizando o julgamento no primeiro grau.

AGRAVO DE INSTRUMENTO. PROCESSUAL CIVIL. IRDR. RECURSO REPETITIVO. TEMA 1007 DO STJ. SUSPENSÃO PROCESSUAL. MODULAÇÃO. LEVANTAMENTO PELO STJ. ADMISSÃO DO RECURSO EXTRAORDINÁRIO. COM LEVANTAMENTO PARCIAL DO SOBRESTAMENTO. VINCULAÇÃO PROVISÓRIA À TESE FIXADA NO STJ.

1. Se já foi julgado o mérito do recurso repetitivo do tema 1007 no Superior Tribunal de Justiça, com a admissão do Recurso Extraordinário e expressa determinação de "suspensão de todos os processos que versem sobre a mesma controvérsia somente em grau recursal, em trâmite no âmbito dos Tribunais e das Turmas Recursais dos Juizados Especiais Federais", os processos devem ter regular prosseguimento com a observância da tese fixada jurídica provisória definida pelo STJ, até que o Pretório Excelso a estabilize (ou não).

2. Sob pena de ruptura do microssistema de demandas repetitivas, sendo o caso de levantamento da suspensão e prosseguimento da tramitação dos processo sobre o tema, deve-se observar, com caráter vinculante provisório, a tese jurídica firmada pelo STJ, pelo menos até que o STF venha a decidir de forma diversa (TRF4, TRS/SC, Agravo de Instrumento no 5032024-6.2020.4.04.0000/SC, Relator Desembargador Federal Paulo Afonso Brum Vaz, j. unânime em 11/09/2020).

13 Têm sido recorrentes no TRF da $4^{\text {a }}$ Região as Reclamações em razão do julgamento de processos durante o período de sobrestamento decorrente da admissão do IRDR: RECLAMAÇÃO. IRDR. SUSPENSÃO DE PROCESSO PARALELO. IRDR. RECLAMAÇÃOO. PROCEDÊNCIA. À época da prolação da decisão reclamada, ainda vigorava a suspensão legalmente prevista no art. 980 do NCPC, uma vez que o IRDR 15 (5054341-77.2016.4.04.0000), ainda que tenha sido distribuído nesta Corte em 13-12-2016, somente veio a ser admitido (vide art. 982, CPC) pela Terceira Seção em 23-08-2017, tendo a suspensão dos processos pendentes na $4^{\mathrm{a}}$ Região iniciado apenas em 01-10-2017. Ademais, embora tenha sido realizado o julgamento de mérito do IRDR pela $3^{\text {a }}$ Seção em 22-11-17, o qual foi devidamente integralizado com o julgamento dos Embargos de Declaração em 27-06-18, é forçoso reconhecer que esta Seção jamais determinou expressamente o levantamento do sobrestamento ao julgar o IRDR 15, suspensão esta que somente cessou em 01-10-2018, por decurso de prazo. Vê-se, pois, que a decisão reclamada foi proferida durante o período de suspensão dos processos (art. 980 do CPC) (TRF4 Reclamação n⿳o 5039674-18.2018.4.04.0000, Terceira Seção, Relator Desembargador Federal Jorge Antônio Maurique, juntado aos autos em $29 / 07 / 2019)$.

RECLAMAÇÃO. IRDR 12. DECISÃO RECLAMADA PROFERIDA À ÉPOCA DA SUSPENSÃO PREVISTA NO CPC. PROCEDÊNCIA. Descabe a prolação de decisão sobre tese objeto de IRDR (Incidente de Resolução de Demandas Repetitivas) durante o período de suspensão previsto nos artigos 980 e 982 do NCPC (TRF4, Reclamação no 5041782-20.2018.4.04.0000, Terceira Seção, Relator Desembargador Federal Paulo Afonso Brum Vaz, juntado aos autos em 03/04/2019). 
Resumindo: levantado o sobrestamento, pelo menos depois de julgado o IRDR, existe a vinculação ao precedente, ainda que provisória. Em face da situação excepcional que se aperfeiçoa com a "janela" criada entre o levantamento da suspensão e a admissão do recurso à superior instância, quando haverá nova suspensão, podem acontecer julgamentos, como efetivamente têm ocorrido, de modo a desafiar a Reclamação dirigida ao tribunal emissor da tese jurídica, sob o fundamento do seu descumprimento:

RECLAMAÇ̃̃O.IRDR 12. DECISÃO RECLAMADA PROFERIDA ÀÉPOCA DA SUSPENSÃO PREVISTA NOCPC. PROCEDÊNCIA. VINCULAÇÃO PROVISÓRIA À TESE FIXADA NO IRDR ATÉ ULTERIOR DELIBERAÇÃO DA INSTÂNCIA SUPERIOR. 1. Determinada a suspensão, durante o período previsto nos artigos 980 e 982 do NCPC, é defeso o julgamento de processo pendente cuja tese esteja afetada em IRDR no respectivo tribunal. 2. Caso levantada a suspensão, depois de julgado o IRDR, independentemente da interposição de recurso à superior instância, existe a vinculação provisória ao precedente até eventual deliberação das instâncias superiores. 3. Não teria sentido e consistiria ruptura do sistema de precedentes do $\mathrm{CPC} / 15$ permitir julgamentos contrários à tese jurídica sufragada em IRDR e respectivos motivos determinantes na eventual janela entre esta decisão e a decisão dos tribunais superiores. A suspensão perderia a sua razão de ser (garantir a segurança jurídica e a isonomia), se persistissem julgamentos contrários à tese proclamada, ainda que sujeita à confirmação (provisória). 4. Reclamação julgada procedente (TRF4, Terceira Seção, Reclamação no 5036022-90.2018.4.04.0000/RS, Relator Des. Federal Paulo Afonso Brum Vaz, j. 24/04/2019).

No âmbito da 3 $3^{\underline{a}}$ Seção do Tribunal Regional Federal da 4 $4^{\underline{a}}$ Região - TRF4, predomina o entendimento no sentido de que a decisão do IRDR não vincula quando houver recurso à Superior Instância, mas os processos devem manter-se sobrestados:

RECLAMAÇÃO. IRDR. SUSPENSÃO DE PROCESSO PARALELO. 1. Conforme o disposto no artigo 987 do CPC, somente quando interposto recurso extraordinário (ou especial) - no caso do IRDR - é que se poderá falar em novo efeito suspensivo. 2. Consultando os autos do IRDR Tema 15 (5054341-77.2016.4.04.0000/SC), constata-se que o INSS interpôs RExt e REsp no final de 2018. Desse modo, considerando que, nos termos do artigo 987, $\S$ 1o, do Código de Processo Civil, os apelos extremos interpostos no âmbito dos incidentes de resolução de demandas repetitivas têm efeito suspensivo automático, entende-se que, independentemente da análise do prazo de suspensão, no atual momento processual (princípios da eficácia processual e da máxima celeridade), deve ser mantido o sobrestamento do feito até o eventual juízo de inadmissibilidade dos recursos especial e extraordinário, ou até o julgamento definitivo pelas Cortes Superiores, caso admitidos (TRF4, Terceira Seção, Reclamação no 5003183-75.2019.4.04.0000, Relator Des. Federal Jorge Antonio Maurique, decisão monocrática em 22/05/2019).

O sobrestamento dos processos, na hipótese, decorre da letra do $\S 1^{o}$ do art. 1.036 do CPC, dispondo que o Presidente ou Vice-Presidente, depois de separar dois ou mais recursos representativos da controvérsia, que serão remetidos ao STF ou ao STJ, para fins de afetação, determinará a suspensão do trâmite de todos os processos pendentes, individuais ou coletivos, que tramitem na sua jurisdição.

Desse modo, a menos que se dê eficácia retroativa à suspensão do § 1ํ do art. 1.036 do CPC, o que não é possível, permanece sem resposta, quanto à vinculação, a possibilidade de julgamento depois de levantado o sobrestamento até a nova suspensão que se dá na admissão do recurso.

A solução do impasse pelo TRF4, determinando o sobrestamento dos processos até o trânsito em julgado da decisão do IRDR, que pode acontecer somente depois de não admitido ou improvido o Recurso Extraordinário no STF, se a questão for de natureza constitucional, arrasta consigo uma externalidade muito negativa que é corolário da demora comumente notada nos julgamentos dos recursos repetitivos no STJ e do STF. Este elastério me parece ser incompatível com o tempo que se considera razoável para a confirmação de uma tese jurídica no sistema de demandas repetitivas, com processos suspensos, que, segundo o CPC, deveria ser, ex vi legis, de no máximo um (1) ano.

De fato, penso que paralisar os processos, por anos a fio, representa um prejuízo maior do que permitir que tenham curso e experimentar o risco de decisões conflitantes e anti-isonômicas.

Vislumbro, em inúmeras situações, maior gravidade no engessamento do Poder Judiciário e no congelamento dos direitos. Sabe-se que o tempo, embora seja necessário para o exercício dos direitos e garantias fundamentais dos litigantes, é o maior inimigo dos direitos. Há direitos que, pela sua natureza, 
são incompatíveis com a demora. Ademais, não custa lembrar que, invariavelmente, o tempo culmina por trazer prejuízo aos mais necessitados, os chamados vulneráveis, que não têm condições de aguardar o desfecho do processo sem sofrer graves prejuízos. O risco marginal, por si só, já lhes causa danos de difícil reparação, como ocorre nos processos que têm por objeto prestações alimentares.

Por fim, não se pode olvidar que, nestes primeiros anos, a maioria dos IRDRs, ao menos na Justiça Federal, são oriundos de processos que tramitam no microssistema dos Juizados Especiais, sendo guiados pelo princípio da celeridade.

No caso de admissão do recurso pela superior instância, caberá ao STJ ou ao STF, conforme o caso, decidir fundamentadamente pela manutenção ou não da suspensão. E a suspensão não é automática, como se verifica da decisão do STJ no REsp no 1794913 , interposto pelo INSS em face da decisão proferida no IRDR 12 do TRF4, que sequer foi afetado à sistemática dos recursos repetitivos, em decisão monocrática do Min. Napoleão Nunes Maia Filho, de 21 de maio de 2019.

\section{Conclusões}

1. Não se coloca em questão a exclusividade dos Tribunais Superiores para a estabilização definitiva das teses jurídicas fixadas pelos Tribunais de Segundo Grau em sede de IRDR. A preocupação é com a possibilidade de decisões conflitantes e anti-isonômicas até que ocorra esta estabilização, propondo-se que, interinamente, se não houver suspensão nacional dos processos, seja esta vinculante no âmbito da jurisdição destes tribunais.

2. O microssistema de demandas repetitivas culmina por ser corrompido na medida em que a construção do precedente é demorada, tanto por problemas estruturais dos tribunais, como por incongruências sistêmicas devidas a interpretações cognitivamente fechadas.

3. É imperativo (re)pensar o microssistema de demandas repetitivas, enquanto sistema cujas partes precisam estar organizativa e estruturalmente concatenadas, de modo que o próprio sistema possa solucionar autorreferencialmente as suas inconsistências normativas e interpretativas.

4. A suspensão dos processos sobre a mesma matéria, admitido o IRDR, não é obrigatória e pode ser prejudicial ao sistema de direitos subjetivos, devendo ser refletida e utilizada parcimoniosamente na medida da necessidade. Em certos casos, com a nota da excepcionalidade, o custo-benefício da suspensão pode ser negativo, recomendando que não haja o sobrestamento.

5. A regra da suspensão da eficácia ope legis da decisão do IRDR, em caso de recurso à superior instância, quando o sobrestamento dos processos se encontra levantado, pode levar a situações inusitadas de julgamentos contrários à tese sufragada, colocando por terra todo o trabalho até então desenvolvido, sobretudo o período de suspensão antecedente que se torna inócuo pelo risco de decisões conflitantes e anti-isonômicas que a ele sobrevém.

6. A manutenção dos processos sobrestados até o trânsito em julgado da decisão, variável que deve acontecer somente depois de julgado o RE no STF, pode ser catastrófica para o próprio o sistema, incluso o microssistema dos Juizados Especiais, que é regido pelo princípio da celeridade.

7. Propõe-se, portanto, que o STJ e o STF assumam um papel ativo na questão da suspensão dos processos, primeiro, analisando de modo compreensivo a sua necessidade, tal como ocorre com a suspensão nacional dos processos, e segundo, admitindo, depois de exame preliminar, a estabilização provisória da tese firmada pelo tribunal de segundo grau no âmbito dos processos que estavam sobrestados na sua jurisdição, até que se torne definitiva com o julgamento do recurso do excepcional.

\section{Referências}

ALVIM, Teresa Arruda. CPC abre debate sobre alcance de suspensão de ações em repetitivos. Consultor Jurídico - Conjur. Disponível em: https://www.conjur.com.br/2017-jun-11/teresa-alvim-cpc-abredebate-suspensao-acoes-repetitivos. Acesso em: 04 ago. 2020. 
BRASIL. Relatório de Gestão do STJ de 2019. Disponível em: http://www.stj.jus.br/sites/portalp/ SiteAssets/Transparencia/Relatorios-de-gestao/Relatorio gestao 2019.pdf. Acesso em 04 ago. 2020.

BRASIL. Relatório de Gestão de 2019 do STF. Disponível em: http://www.stf.jus.br/arquivo/ cms/centralDoCidadaoAcessoInformacaoGestaoEstrategica/anexo/2020 $01 \quad 24 \quad 13.08$ RelatoriodeAtividades2019 completo.pdf. Acesso em 04 ago. 2020.

BRASIL. STJ, Terceira Turma, REsp nº 1.846.109 - SP, Relatora Ministra NANCY ANDRIGHI, julgado em $10 / 12 / 2019$

BRASIL. TRF4, Terceira Seção, Reclamação nº 5003183-75.2019.4.04.0000, Relator Des. Federal Jorge Antonio Maurique, decisão monocrática em 22/05/2019.

BRASIL. TRF4, Reclamação n⿳o 5039674-18.2018.4.04.0000, Terceira Seção, Relator Desembargador Federal Jorge Antônio Maurique, juntado aos autos em 29/07/2019.

BRASIL. TRF4, Reclamação n⿳o 5041782-20.2018.4.04.0000, Terceira Seção, Relator Desembargador Federal Paulo Afonso Brum Vaz, juntado aos autos em 03/04/2019.

BRASIL. TRF4, Terceira Seção, Reclamação nº 5036022-90.2018.4.04.0000/RS, Relator Des. Federal Paulo Afonso Brum Vaz, j. 24/04/2019.

BRASIL. TRF4, AG no 5019431-53.2018.4.04.0000, Turma Regional Suplementar de Santa Catarina, Relator Des. Federal Celso Kipper, juntado aos autos em 21/03/2019.

BRASIL. TRF4, IRDR no 5046607-70.2019.4.04.0000, Terceira Seção, Relator Desembargador Federal Fernando Quadros da Silva, juntado aos autos em 29/05/2020.

BRASIL. TJ/SP, IRDR nํ 0023203-35.2016.8.26.0000, Rel. Desembargador Francisco Loureiro.

BRASIL, TRF4, TRS/SC, Agravo de Instrumento nº 5032024-6.2020.4.04.0000/SC, Relator Desembargador Federal Paulo Afonso Brum Vaz, j. unânime em 11/09/2020.

LEMOS, Vinícius Silva. A falácia na aplicação da tese jurídica fixada em IRDR: a função meramente preparatória do incidente. In: Processo, jurisdição e efetividade da justiça II [Recurso eletrônico on-line] organização CONPEDI/CESUPA. Coordenadores: Celso Hiroshi Iocohama; Sérgio Henriques Zandona Freitas - Florianópolis: CONPEDI, 2019.

NUNES, Dierle; SOUZA VIANA, Antônio Aurélio. Suspensão integral de processos em recursos repetitivos preocupa. Consultor Jurídico, 31 de maio de 2017, disponível em: https://www.conjur. com.br/2017-mai-31/opiniao-suspensao-integral-processos-repetitivos-preocupa. Acesso em: 03 ago. 2020.

MARINONI, Luiz Guilherme. O "problema” do incidente de resolução de demandas repetitivas e dos recursos extraordinário e especial repetitivos. Revista de Processo. vol. 249. Ano 40. São Paulo: RT, nov. 2015, p. 399-419.

PEIXOTO, Ravi. O IRDR e a suspensão de processos. Disponível em: emporiododireito.com.br/o-irdre-a-suspensao-de-processos-por-ravi-peixoto/. Acesso em: 04 ago. 2020.

PINTO, Christian Barros. Impossibilidade de sobrestamento de cumprimento de sentença pela admissão de Incidente de Resolução de Demandas Repetitivas. Disponível em: https:// www.academia.edu/32058320/Impossibilidade de sobrestamento de cumprimento de senten\%C3\%A7a_pela_admiss\%C3\%A30_de_Incidente_de_Resolu\%C3\%A7\%C3\%A30_de_ Demandas Repetitivas. Acesso em: 15 set. 2020.

TEMER, Sofia. Incidente de resolução de demandas repetitivas. 2. ed.. Salvador: JusPodivm, 2017. 